* Mestre em Direito Constitucional pela Universidade de Fortaleza (UNIFOR).LLM em Direito Corporativo pelo Instituto Brasileiro de Mercado de Capitais do Rio de Janeiro (IBMEC-RJ). Graduado em Direito pela Universidade de Fortaleza (UNIFOR).E-mail: tedpontes@outlook. com.

** Doutora em Direito Comercial pela Universidade de São Paulo (USP). Professora Titular do Programa de Pós-Graduação da Universidade de Fortaleza (UNIFOR). Professora Adjunta da Faculdade de Direito da Universidade Federal do Ceará (UFC). Advogada. E-mail: ucaminha@ gmail.com.

\section{UMA ANÁLISE ECONÔMICA DA ALIENAÇÃO FIDUCIÁRIA EM GARANTIA DOS BENS IMÓVEIS}

\author{
AN ECONOMIC ANALYSIS OF THE CHATTEL \\ MORTGAGE ON IMMOVABLE PROPERTIES
}

\author{
* Ted Luiz Rocha Pontes \\ **Uinie Caminha
}

Resumo: O presente trabalho teve como objetivo analisar sob o enfoque do direito e economia o instituto jurídico da alienação fiduciária em garantia de bens imóveis, instituído no ordenamento pátrio pela Lei Federal de no. 9.514/1997, comparando-o com a garantia real imobiliária dada pela Hipoteca, usando-se uma análise econômica dos institutos. Verificou-se a existência de dados que demonstram a redução da taxa de inadimplência do crédito concedido e garantido pelo instituto da alienação fiduciária, bem como o aumento da segurança jurídica na execução da garantia, em comparação com as dificuldades verificadas para a execução da garantia hipotecária, demonstrando uma eficiência econômica.

Palavras-chave: Alienação fiduciária; mercado imobiliário; SFI; hipoteca; SFH.

Abstract: This paper aims to examine - under the approach of law and economics - the legal institute of the chattel mortgage in the real estate market. This institute was established by the enactment of Federal Law no. 9514/1997 and is compared to an ordinary mortgage. The use of data verified the existence of the reduction of the default rates concerning the credits granted and guaranteed by the Institute of liens, as well as increasing the legal certainty of the enforcement of the chattel mortgage in comparison with the difficulties encountered in the enforcement of the ordinary mortgage; thus, showing an economic efficiency.

Keywords: Chattel mortgage; housing market; SFI; mortgage; SFH.

Como citar: COIMBRA, Rodrigo; WITTCKIND, Ellara Valentini. A livre circulação de trabalhadores e a não discriminação ao migrante na União Europeia: digressões acerca da fraternidade e do reconhecimento nas relações de trabalho. Scientia Iuris, Londrina, v. 20, n. 1, p.220-246 abr. 2016. DOI: 10.5433/2178-8189.2016v20n1p220. ISSN: 2178-8189. 


\section{INTRODUÇÃO}

O mercado imobiliário é importante para o desenvolvimento econômico e social do Brasil, porquanto se por um lado possui uma alta capacidade de geração de empregos ${ }^{1}$ e circulação de riquezas, por outro possibilita o acesso da população à moradia e, por consequência, a redução do défice habitacional.

A importância do segmento justificou a criação, em 1964, do Sistema Financeiro da Habitação, com o objetivo de propiciar a compra da moradia pela população, por meio do incentivo a concessão de financiamentos imobiliários. Em tal sistema financeiro os recursos são provenientes do Fundo de Garantia por Tempo de Serviço e do Sistema Brasileiro de Poupança e Empréstimos.

Entretanto, em função da elevada inadimplência, da demora na execução das garantias hipotecárias, do descasamento entre as taxas de captação e remuneração e da insegurança jurídica ocasionada pela judiciliazação das relações jurídicas, o Sistema Financeiro da Habitação entrou em crise, culminando, ao final, com a extinção do Banco Nacional da Habitação.

É no contexto de necessidade de reerguer o mercado imobiliário, de reduzir a taxa de inadimplência e de conceder mais segurança aos financiamentos concedidos, com vistas a possibilitar tanto a construção de novos empreendimentos imobiliários, como a sua comercialização, que é elaborada e promulgada a Lei Federal de $\mathrm{n}^{\mathrm{o}}$. 9.514, de 20 de novembro de 1997. Tal Lei Federal instituiu o Sistema de Financiamento Imobiliário para possibilitar o investimento via mercado de capitais, criando o Certificado de Recebível Imobiliário de livre circulação e, por fim, estabeleceu a possibilidade de contratação de alienação fiduciária em garantia de bem imóvel, em uma tentativa de superar os entraves da hipoteca e, portanto, aumentar a segurança jurídica do sistema.

A referida garantia, objeto do presente trabalho, tinha - e continua tendo - como objetivo superar os entraves vivenciados pela garantia hipotecária nos financiamentos imobiliários contratados, possibilitando uma célere execução e venda do imóvel dado em garantia, por meio de procedimento de público leilão descrito no diploma legal. Ademais, foi possibilitado, justamente para garantir a existência de contratos homogêneos, que todas as pessoas contratassem a alienação fiduciária, não sendo, então, exclusiva das entidades integrantes do

\footnotetext{
${ }^{1}$ A Construção Civil gerou, aproximadamente, 1,7 milhões de postos de trabalho entre 2002 e 2012. Fonte:
} Secovi - Disponível em http://www.secovi.com.br/files/Downloads/balaco-mercado-imobiliario-2012pdf. 


\section{SFI.}

Metodologicamente, esta investigação se classifica da seguinte forma: bibliográfica, quanto ao tipo, porquanto o conhecimento foi buscado em livros doutrinários, artigos científicos, dissertações de mestrados, teses de doutorado, enfim, em entendimentos dos diversos autores sobre a problemática delineada; quanto à utilização dos resultados, aplicada; quanto à natureza, qualitativa. Buscaram-se, ainda, os entendimentos dos tribunais sobre o assunto pesquisado e os indicadores econômicos atrelados à utilização do instituto de garantia objeto desta pesquisa, como a diminuição da inadimplência e/ou aumento da segurança jurídica na execução da garantia dada.

Desta feita, o objetivo do presente trabalho consiste em analisar, sob o enfoque do direito e economia, o instituto jurídico da alienação fiduciária em garantia de bens imóveis, comparando-a com o instituto da hipoteca, garantia real sobre bens imóveis de terceiro. Para cumprir com tal desiderato, o trabalho foi divido em três tópicos, sendo o primeiro destinado à análise do direito real de garantia sobre bem próprio denominado de alienação fiduciária de bem imóvel. O segundo tópico visa elencar alguns conceitos econômicos que irão propiciar a análise econômica empreendida no terceiro e último tópico, cujo ponto central da análise consiste em saber se o instituto jurídico em questão está sendo aplicado de maneira eficiente e se cumpriu - ou está cumprindo - com os objetivos econômicos justificadores de sua opinião, no que tange, por exemplo, a taxa de inadimplência dos contratos de financiamento imobiliário garantidos pela alienação fiduciária em comparação com os contratos de financiamento garantidos pela hipoteca.

\section{ALIENAÇÃO FIDUCIÁRIA DE BENS IMÓVEIS 1.1 PROBLEMA DA PROPRIEDADE FIDUCIÁRIA NO BRASIL}

O instituto jurídico da alienação fiduciária em garantia de bens imóveis foi instituído no Brasil com o advento da Lei Federal de $n^{0}$. 9.514, de 20 de novembro de 1997, juntamente com a criação do Sistema de Financiamento Imobiliário - SFI, com vistas a dotar de maior garantia os financiamentos imobiliários concedidos. Muito embora, vale salientar, já fosse previsto no ordenamento jurídico pátrio desde a Lei Federal de $\mathrm{n}^{\circ}$. 4.728, de 14 de julho de 1965, a alienação fiduciária sobre bens móveis.

O contexto de elaboração da Lei Federal de nº. 9.514/1997 era o de 
necessidade de captação de novos recursos para viabilizar a consecução de empreendimentos imobiliários, porquanto constatou-se um decréscimo dos financiamentos firmados no âmbito do tradicional Sistema Financeiro da Habitação - SFH. Restiffe Neto (2009, p. 20) identifica "a ineficiência do tradicional sistema jurisdicional de recuperação dos créditos e de retomada dos imóveis, por fragilidade da garantia hipotecária" como uma das causas do exaurimento dos recursos disponíveis, além da "elevada inadimplência, por decréscimo da renda pessoal do adquirente mutuário ativo ou aposentado, em contraste com a disparada inflacionária e a consequente elevação do valor gravoso de atualização das prestações, sobretudo do saldo devedor". Viu-se, nessa época, o ajuizamento de incontáveis demandas questionando a validade das cláusulas contratuais, a validade do procedimento de execução extrajudicial previsto no Decreto-Lei de $n^{\circ}$. 70, de 21 de novembro de 1966, a aplicação de sistema de amortização, dentre outros questionamentos.

Tal situação ocasionou uma alta insegurança jurídica, porquanto as instituições participantes do SFH não tinham como prevê o resultado final das demandas e, por consequência, dos custos reais de determinado financiamento concedido. Pode-se citar, por exemplo, a súmula 308 do STJ que, segundo esse entendimento, a "hipoteca firmada entre a construtora e o agente financeiro, anterior ou posterior à celebração da promessa de compra e venda, não tem eficácia perante os adquirentes do imóvel", muito embora a concessão de tal garantia real tivesse sido condição essencial para a concessão do financiamento imobiliário e, por isso, para a realização das promessas de compra e venda.

Com o intento de criar um mecanismo de captação junto ao mercado de capitais, o referido diploma legal instituiu o SFI e os institutos jurídicos necessários para viabilizar a destinação dos recursos via mercado primário e secundário de capitais. Nesse diapasão, Alvim Neto (apud ABECIP, 1999, p. 11) já afirmava, pouco tempo após a promulgação da legislação, que o "SFI objetiva carrear continuadamente recursos imensos para o mercado imobiliários".

É nesse cenário que a alienação fiduciária em garantia de bens imóveis é instituída na legislação brasileira, tendo por objetivo propiciar o desenvolvimento do mercado imobiliário de forma a garantir a produção de créditos homogêneos e de fácil circulação, dotando de mais segurança e agilidade a execução da garantia concedida no âmbito do financiamento imobiliário. Chalhub (2006, p. 203), comentando o assunto, afirma visar a "lei, assim, que o mercado ajuste suas linhas de operação, de forma a viabilizar a constituição de créditos homogêneos, sem obstáculos no mercado", tal escopo 
se evidencia na possibilidade de qualquer pessoa contratar esse instrumento:

Com a generalização, o legislador deixa clara sua intenção de dotar o setor imobiliário, em toda a sua amplitude, de um novo instrumento para dinamização de suas atividades, em atenção à sua função multiplicadora na economia e à sua capacidade de geração de empregos em larga escala e, em especial, viabilizar o funcionamento do mercado secundário de créditos imobiliários. (CHALHUB, 2006, p. 202-203).

A importância da generalização explicitada pelo autor decorre do fato de muitas operações no mercado imobiliário serem firmadas entre o construtor e o comprador. Nesses casos, com a possibilidade de contratação da alienação fiduciária em garantia, o crédito já poderá ser constituído - e garantido - de acordo com as regras do mercado secundário, possibilitando, assim, a cessão por parte do construtor do crédito garantido para, por exemplo, uma companhia securitizadora, podendo esta emitir os Certificados de Recebíveis Imobiliários - CRI's, correspondentes. Vale frisar que os financiamentos hoje concedidos no âmbito do SFH, com recursos do Sistema Brasileiro de Poupanças e Empréstimos - SBPE, e do Fundo de Garantia por Tempo de Serviços - FGTS, são garantido, em sua grande maioria, pelo instrumento da alienação fiduciária em garantia ${ }^{2}$.

Convém, então, analisar o instituto da alienação fiduciária em garantia sobre bens imóveis, tendo, para tanto, como ponto de partida a delimitação de suas características, de seus procedimentos e a sua diferenciação para a garantia real sobre bem alheio denominada de hipoteca.

A alienação fiduciária em garantia de bem imóvel, nos termos do art. 22 da Lei Federal de nº 9.514/1997, “é o negócio jurídico pelo qual o devedor, ou fiduciante, com o escopo de garantia, contrata a transferência ao credor, ou fiduciário, da propriedade resolúvel de coisa imóvel". Percebe-se que o domínio do imóvel será transferido sob condição resolutiva ao credor, com o objetivo único de garantir a operação imobiliária firmada. Decorrendo daí a primeira característica desse instituto, o credor garantido passa a ser proprietário do bem, não sendo, portanto, um caso clássico de garantia real sobre imóvel alheio. Por outro lado, o devedor tem o direito de reaver o imóvel quando do pagamento

${ }^{2}$ Em 2009, 87\% dos financiamentos imobiliários concedidos pela Caixa Econômica Federal já eram garantidos pela Alienação Fiduciária em Garantia. Fonte: SIACI/CEF

SCIENTIA IURIS, Londrina, v.20, n.1, p.221-248 abr.2016 | DOI: 10.5433/2178-8189.2016v20n1p221 
integral, sendo, então, proprietário sob condição suspensiva.

Nesse contexto, Restiffe Neto (2009, p. 68) salienta que "a fidúcia como garantia dominial oferece dúplice proteção legal na esfera dos interesses jurídicos de cada parte contratante". Essa dupla garantia, tanto para o credor como para o devedor, é de extrema relevância para os objetivos econômicos e sociais pretendidos pelo legislador com a instituição do referido meio de garantia. Percebe-se que a proteção aos contratantes é estabelecida na legislação de maneira equilibrada, se por um lado "ao proprietário fiduciário, que se investe sob condição resolutiva da titularidade propiciadora de segurança para receber o crédito garantido, na eventualidade de inadimplemento", por outro garante-se ao devedor fiduciante em dia com pagamento das parcelas da amortização do financiamento a "fruição útil atual e a novidade legal de garantia real de retransferência ou reversão futura, portanto, sob condição suspensiva, da propriedade resolvida" (RESTIFFE NETO, 2009, p. 68). Tal equilíbrio, por certo, objetiva o desenvolvimento do mercado de crédito imobiliário, resguardando direitos tantos dos financiadores como dos financiados.

Alvim Neto (apud ABECIP, 1999, p. 8) em parecer elaborado para a Associação Brasileira de Crédito Imobiliário e Poupança constatou, em função do sistema de garantia e execução criados, que a alienação fiduciária de imóveis se constitui "poderosíssima alavanca para o desenvolvimento de nossa sociedade, através de alterações profundas a serem provocadas em nossa economia, viabilizando que se incremente a produção de imóveis". É, justamente, com base nessa função e desiderato da alienação fiduciária que se deve averiguar e analisar as suas demais características.

Importa, então, perceber e analisar qual a condição resolutiva da propriedade fiduciária e sob quais condições ela se concretiza, bem como quais são os procedimentos necessários para a execução da garantia fiduciária concedida. A primeira constatação que se pode fazer reside no fato da condição resolutiva da propriedade fiduciária ser a restituição integral do financiamento concedido acrescido dos juros e encargos contratados. Não poderia ser diferente, haja vista a alienação fiduciária de bens imóveis ser instrumento acessório garantidor de um contrato principal, qual seja um contrato de financiamento (RESTIFFE NETO, 2009, p. 72).

$\mathrm{O}$ art. 25 da Lei Federal de $n^{\circ} .9 .514 / 1997$ determina que "com o pagamento da dívida e seus encargos, resolve-se, nos termos deste artigo, a propriedade fiduciária do imóvel". A resolução prevista é de pleno direito, não podendo o Fiduciário se escusar de fornecer a quitação devida e, com isso, 
possibilitar a reversão da propriedade fiduciária. Melhim Namem Chalhub frisa o fato de o pagamento ser:

o evento caracterizador do implemento da condição, criando automaticamente para o credor a obrigação de dar quitação ao fiduciante e viabilizando para este a recuperação da plena propriedade do imóvel. (CHALHUB, 2006, p. 214).

A própria legislação, vale salientar, impõe multa pecuniária de meio por cento ao mês do valor do contrato ao Fiduciário que se recusar, indevidamente, a entregar, no prazo de 30 dias a contar da liquidação da dívida, o correspondente termo de quitação. É certo, no entanto, que a condição resolutiva se perfaz no momento do pagamento, sendo o termo de quitação documento hábil a justificar a averbação no registro de imóveis competente, podendo o fiduciante, caso o fiduciário não cumpra tal obrigação por vontade própria, requerer em juízo a respectiva obrigação de fazer.

Sendo o pagamento a condição resolutiva capaz de reverter a propriedade fiduciária em favor do devedor fiduciante, o inadimplemento será, portanto, a condição capaz de consolidar a propriedade plena em favor do fiduciário. Contudo, tal consolidação terá como objetivo básico a venda do referido imóvel em condições de mercado, por meio da realização de públicos leilões, seguindo o procedimento previsto na Lei Federal de $n^{\circ}$. 9.514/1997.

Para consolidação da propriedade, em função do inadimplemento, em nome do fiduciário tem-se que seguir os procedimentos previstos no art. 26 e seguintes do já citado diploma legal. Ademais, o contrato de alienação fiduciária deve prever um prazo de carência após o qual o fiduciário deverá intimar pessoalmente, por meio do Registro de Imóveis competente, o fiduciante para que este satisfaça as prestações vencidas e as que vencerem no prazo da notificação e demais acréscimos autorizados legalmente, no prazo de quinze dias. Decorrido o prazo de quinze dias sem que ocorra o pagamento devido, o Oficial de Registro de Imóveis competente deve averbar, com a comprovação do pagamento do Imposto de Transmissão de Bens Imóveis Inter-Vivos - ITBI, a consolidação da propriedade em favor do fiduciário, conforme determina 0 $\S 7^{\circ}$ do art. 26 da Lei Federal de $n^{\circ}$. 9.514/1997.

Após a consolidação da propriedade em favor do fiduciário, a lei determina que seja realizado, no prazo de trinta dias a contar da data do registro da consolidação, o primeiro público leilão para venda do referido imóvel. 
Percebe-se que a intenção legislativa é a de promover a venda do imóvel, não sendo permitido que o fiduciário, muito embora a propriedade tenha sido consolidada em seu nome, avoque para si a propriedade plena, com todos os direitos a ela inerentes, do em imóvel, porquanto a contratação da alienação fiduciária teve como objetivo a garantia de um contrato de financiamento e não a transferência do imóvel, em si.

No primeiro público leilão, não serão aceitas lances inferiores ao valor do imóvel estabelecido no contrato de alienação fiduciária, conforme determina o art. 24, IV, da Lei Federal de nº. 9.514/1997. Essa impossibilidade se dá porque as partes, fiduciário e fiduciante, devem no momento da celebração do contrato de alienação fiduciária estabelecer o valor do imóvel e seu mecanismo de atualização para venda no primeiro público leilão. Essa determinação é relevante porque visa estabelecer uma solução de mercado para a inadimplência do fiduciante, tendo em vista que o imóvel, pelo menos em tese, seria vendido pelo preço estabelecido no contrato de alienação fiduciária, o que garantiria ao fiduciante o recebimento dos valores que superassem a dívida existente.

Contudo, nem sempre é possível a venda o imóvel pelo preço determinado em contrato, por isso a legislação prevê que "se, no primeiro público leilão, o maior lance oferecido for inferior ao valor do imóvel, estipulado na forma do inciso VI do art. 24, será realizado o segundo leilão, nos quinze dias seguintes" (BRASIL, 1997, p. 9). No segundo leilão, o imóvel será vendido pelo maior lance ofertado, desde que não inferior ao valor da dívida com os acréscimos permitidos em Lei. Em caso de venda do imóvel no público leilão por valor superior ao da dívida, o fiduciário deve, no prazo de cinco dias após a venda no leilão, entregar ao devedor à quantia que sobejar, fato esse que importará em reciproca quitação.

Por outro lado, inexistindo lance superior ao valor do débito e dos acréscimos legais, "considerar-se-á extinta a dívida e exonerado o credor da obrigação" (BRASIL, 1997) de entregar de qualquer valor. Na prática, essa situação importa na assunção do risco e do prejuízo pelo credor, porquanto o preço (mecanismo de troca de informações no mercado) do imóvel não supera o valor da dívida existente, contudo o credor não poderá cobrar do devedor a diferença, como ocorre na alienação fiduciária de bens móveis, sendo, na realidade, obrigado a dá quitação do financiamento. Melhim Namem Chalhub, em parecer requisitado pela Associação Brasileira de Crédito Imobiliário e Poupança - ABECIP, justifica esse tratamento diferenciado, de assunção do risco de preço e do prejuízo pelo credor, "como uma compensação pela maior 
eficácia da realização da garantia na alienação fiduciária de bens imóveis, notadamente pela celeridade do processo" Chalhub (apud ABECIP, 1999, p. 54).

Vale, ainda, salientar que todo o procedimento acima explicitado é extrajudicial, circunstância essa que enseja questionamentos quanto a sua validade perante o Poder Judiciário. Contudo, Negrato (2010, p. 87) constata que a jurisprudência majoritária se consolidou no sentido de entender por válido e constitucional o procedimento de execução extrajudicial previsto na Lei Federal de $n^{\circ} .9 .514 / 1997$, garantindo segurança jurídica à utilização do instituto da alienação fiduciária de bens imóveis e, por consequência, do seu procedimento célere de execução extrajudicial.

Outra importante característica da alienação fiduciária de bens imóveis consubstancia-se na criação de um patrimônio de afetação não sujeito às execuções concursais promovidas em face seja do credor ou em face do devedor (CHALHUB, 2006, p. 299). Tal patrimônio separado decorre do mecanismo de dupla garantia instituído pela alienação fiduciária, porquanto o bem imóvel dado em alienação fiduciária tem como único objetivo garantir o crédito concedido, sendo transferida ao credor fiduciário sob condição resolutiva a propriedade do bem. No entanto, ao devedor fidiciante é resguardado a propriedade sob condição suspensiva, existindo verdadeiro direito real de reaver, com a quitação do financiamento, a condição de proprietário pleno do imóvel.

A característica do desdobramento da posse do imóvel também decorre da transferência da propriedade fiduciária. Ao devedor fiduciante é assegurada à posse direta do bem dado em garantia, usufruindo por sua conta e risco o imóvel em questão. Diz que a posse se dá por sua conta e risco por serem de responsabilidade do devedor fiduciante, possuidor direto, o pagamento de todos os tributos, encargos e despesas incidentes sobre o imóvel, como, por exemplo, o Imposto sobre Propriedade Predial Territorial Urbana - IPTU, e despesas condominiais, se existentes.

De igual forma, em função do desmembramento da posse operada pela contratação e registro da alienação fiduciária em garantia, aos dois possuidores, direto e indireto, são autorizados a adoção de atos de conservação e defesa do bem dado em garantia. Nesse diapasão, Restiffe Neto salienta:

Assim, como é pela natureza das coisas que um direito eventual condicionado (pendente), merece tutela conservativa, a lei especial, ao outorgar a respectiva permissão de exercício 
de atos de conservação (de defesa, principalmente) ao titular atual do direito eventual futuro de propriedade sob condição suspensiva (fiduciante), não a negou ao titular do direito atual de propriedade, pendente sob condição resolutiva (fiduciário). (RESTIFFE NETO, 2009, p. 104).

Percebe-se que tanto ao fiduciário como ao fiduciante é permitida - até incentivada - a adoção de medidas de proteção e resguardo do imóvel objeto do pacto de alienação fiduciária. Tal possibilidade decorre da existência de verdadeiro de direito de propriedade sob condição resolutiva para fiduciário e direito de propriedade sob condição suspensiva para o fiduciante. Dito isso, importa, nesse ponto, verificar quais são os limites da propriedade fiduciária imóvel, distinguindo-a do direito à propriedade em sua plenitude.

O limite básico existente refere-se à impossibilidade de livre uso do imóvel quando da consolidação da propriedade em favor do fiduciário. O procedimento previsto na Lei Federal de $n^{\circ}$. 9.514/1997 determina a realização de público leilão, com vistas a possibilitar a venda a preço de mercado do imóvel. Essa determinação tem como justificativa o fato da operação principal ser um contrato de mútuo e, como tal, estabelecer a obrigação do devedor restituir o capital disponibilizado acrescido dos juros devidos, determinando, por outro lado, que ao credor somente cabe o recebimento do recurso inicialmente disponibilizado e dos juros respectivos. Justamente por isso a legislação estabelece um procedimento de valoração do imóvel pelo mercado, possibilitando, caso o preço dado pelo mercado seja superior à dívida, a entrega da diferença ao fiduciante, vedando, portanto, que o fiduciário haja de maneira distinta ao escopo da contratação da alienação fiduciária, qual seja o de garantir o contrato de financiamento principal. A alienação fiduciária é instrumento acessório com escopo único de garantia.

Sendo um direito real com escopo de garantia, vale, então, distingui-la da garantia real tradicional da hipoteca. A primeira e grande distinção consiste no fato da hipoteca ser um direito real sobre bem imóvel alheio, enquanto a alienação fiduciária é um direito real sobre imóvel próprio. Decorrem dessa distinção básica relevantes consequências, sendo a principal delas o fato do bem alienado fiduciariamente não se submeter ao regime concursal instaurado em face do devedor, enquanto na hipoteca o bem imóvel é efetivamente arrecadado e o crédito correspondente deve, somente, ser inscrito no Quadro Geral de Credores na categoria de crédito com garantia real. (CHALHUB, 2006, p. 
198). Assim, sendo, a alienação fiduciária em garantia de bens imóveis é mais eficiente no que tange a resguardar o bem dado em garantia, assegurando uma maior eficácia na execução do crédito garantido.

Por outro lado, nos créditos garantidos por meio da alienação fiduciária, o risco do preço do imóvel é do credor, tendo em vista que, nos casos em que não forem apresentadas ofertas no valor da dívida para a compra do imóvel, o devedor será exonerado do débito, devendo o credor dar-lhe quitação. Tal obrigação inexiste nos créditos garantidos por hipotecas, podendo o credor cobrar do devedor o saldo remanescente da dívida ou, ainda, concorrer com os credores quirografários no valor que ultrapassar o preço do bem gravado com a cláusula hipotecária (NEGRATO, 2010, p. 76).

Além do acima exposto, tem-se que a própria instituição da alienação fiduciária teve como um dos desideratos substituir a hipoteca como mecanismo de garantia básico dos financiamentos imobiliários, seja no âmbito do SFI ou do SFH. Tanto assim o é que o Conselho Monetário Nacional - CMN, por meio da Resolução de $n^{\circ}$. 2.480, de 26 de março de 1998, pouco tempo depois da promulgação da Lei Federal de $n^{\circ}$. 9.514/1997, autorizou a contratação da alienação fiduciária em garantia nos financiamentos firmados no âmbito do $\mathrm{SFH}$, antes restritos à hipoteca.

\section{CONCEITOS ECONÔMICOS}

A promulgação da Lei Federal de nº 9.514/1997 e, por consequência, a criação da alienação fiduciária em garantia de bens imóveis no Brasil teve os seguintes intentos econômicos: o de propiciar a destinação de recursos ao mercado imobiliário, o de garantir segurança jurídica ao processo de execução da garantia concedida e, por via disso, a diminuição da inadimplência, o de estabelecer procedimentos de mercado capazes de impulsionar a concessão de financiamentos imobiliários no Brasil, superando a crise vivenciada no âmbito do SFH.

Luciano Benetti Timm e Tatiana Druck (2007, p. 10) salientaram que a "alienação fiduciária constitui-se, portanto, em um estímulo à celebração de negócios, ficando os agentes econômicos mais seguros contra inadimplementos”. Contudo, nesse mesmo artigo, os citados autores identificaram situações que poderiam impossibilitar que a alienação fiduciária alcançasse o seu resultado esperado. Nesse contexto, o questionamento que se pode propor e analisar pelo método do direito e economia é o seguinte: será que o instituto jurídico 
da alienação fiduciária alcançou o seu objetivo econômico de propiciar uma diminuição na inadimplência dos financiamentos imobiliários?

Para tentar responder ao questionamento acima, faz-se necessária elencar e definir alguns conceitos nitidamente econômicos, bem como comparar os dados econômicos e a bibliografia existente. Primeiramente, é importante conceituar o que se entende por mercado, por preço e por custos de transação, incluindo nesse último a questão da segurança jurídica. Tais definições são importantes para analisar, sob o enfoque do direito e economia, o instituto da alienação fiduciária.

Sob uma perspectiva da escola austríaca, o mercado, "não é um lugar", sendo antes "um processo, é a forma pela qual, ao vender e comprar, ao produzir e consumir, as pessoas estão contribuindo para o funcionamento global da sociedade. (MISES, 2009, p. 27). A contribuição para o funcionamento global da sociedade se dá por meio da transmissão de informações que propiciará a produção e circulação de riquezas, tendo em vista que as informações, para o autor, não estão dadas para todos os homens, estando, antes, dispersas na mente de cada um e só sendo transmitida no mercado, por meio do preço.

Essa forma de entender o mercado decorre da primazia que os austríacos dão a ação humana, sendo essa ação a conduta deliberada de empreender em proveito próprio, afirmando que "os bens, as mercadorias, as riquezas e todas as demais noções de conduta não são elementos da natureza, mas sim elementos da mente e da conduta humana" (MISES, 2009, p. 111). Destacase a função empresarial da ação humana como o cerne do desenvolvimento econômico e do conceito de sociedade, haja vista serem os empresários, com suas atuações subjetivas, que produzem e circulam as riquezas. Frise-se que o lucro empresarial surge quando o "empresário descobre uma oportunidade de ganho que até aí tinha passado despercebido e atua em conformidade para tirar partido da mesma" (DE SOTO, 2010, p. 19), sendo o risco um custo do processo de produção empresarial.

Esse conceito de mercado se encaixa ao presente trabalho porque a instituição da alienação fiduciária em garantia visava a ampliação do mercado imobiliário por meio da criação de mecanismos de negociação de títulos e da transmissão de informações aos agentes econômicos. Pode-se citar o seguinte exemplo: o banco A concede ao homem B o financiamento imobiliário com pacto adjeto de alienação fiduciária; essa destinação de recursos transmite ao construtor $\mathrm{C}$ a informação de que existem recursos aptos a viabilizarem a venda de unidades habitacionais construídas; por sua vez, a venda de unidades 
habitacionais transmite ao Banco A a informação da existência de unidades disponíveis, e assim sucessivamente, com a construção de novas unidades habitacionais e a concessão de novos financiamentos. Ademais, vale frisar que o próprio procedimento de leilão público previsto na Lei Federal de $n^{\circ}$. 9.514/1997 transmite aos demais agentes econômicos a informação da execução extrajudicial da garantia e, com isso, a informação da segurança jurídica propiciada pelo instituto, possibilitando, em tese, a diminuição dos juros do financiamento concedido, fato esse que possibilitaria a concessão de novos financiamentos.

Sendo o conceito de mercado o acima exposto, tem-se que o preço é o meio de troca das informações no mercado. É por meio do preço que é possível a realização de cálculos econômicos por parte dos empresários e, com isso, a produção e circulação das riquezas. Nesse sentido Mises (2009, p. 40) afirma:

[...] os cálculos do homem de negócios se baseiam todos no fato de que, na economia de mercado, os preços em dinheiro dos bens não só informam o consumidor, como fornecem ao negociante informações de importância vital sobre os fatores de produção, porquanto o mercado tem por função primordial determinar não só o custo da última parte do processo de produção, mas também dos passos intermediários.

No preço, portanto, estarão consubstanciadas todas as informações vitais de determinado processo produtivo, justificando, ou não, a decisão de empreender e dispender recursos em determinado segmento de mercado. Essa definição se adequa ao presente trabalho, porquanto o preço dos financiamentos imobiliários é representado pela taxa de juros contratada. Então, a diminuição da taxa de juros representa a informação que o custo para a concessão do financiamento imobiliário também decresceu, o que poderia, em tese, ser decorrência da alienação fiduciária em garantia.

Importa, agora, delimitar o conceito de custos de transação e a sua relação com a insegurança jurídica. Pinheiro e Saddi (2005, p. 61) comparam os custos de transação com a força do atrito estudada na física, sendo aqueles os custos incidentes e necessários para iniciar uma transação econômica, assim como o atrito é a força necessária para iniciar o movimento de um determinado corpo inerte. A definição e a importância dos custos de transação foram delimitadas por Ronald Coase nos trabalhos institulados: The Nature of 
the Firm e The Problem of Social Cost.

Zybertztajn e Sztajn (2005, p. 1) definem o Teorema de Coase da seguinte forma: "em um mundo hipotético sem custos de transação (pressuposto da Economia Neoclássica), os agentes negociarão os direitos, independentemente da sua distribuição inicial, de modo a chegar à sua alocação eficiente". Contudo, tal situação inexiste na prática, pois, conforme afirma o próprio Coase (1960, p. 15), os custos de transação sempre serão positivos, tendo em vista que se referem aos custos para propiciar a negociação dos direitos, notadamente o direito de propriedade, sendo compreendidos os custos de cinco atividades:

Primeiro, a atividade da busca pela informação sobre regras de distribuição de preço e qualidade das mercadorias, sobre insumos de trabalho e a busca por potenciais compradores e vendedores, assim como de informação relevante sobre o comportamento desses agentes e a circunstância em que operam. Segundo, a atividade da negociação, que será necessária para determinar as verdadeiras intenções e os limites de compradores e vendedores na hipótese de a determinação dos preços ser endógena. Terceiro, a realização e a formalização dos contratos, inclusive o registro nos órgãos competentes, de acordo com as normas legais, atividade fundamental do ponto de vista do direito privado, já que é o que reveste o ato das garantias legais. Quarto, o monitoramento dos parceiros contratuais com o intuito de verificar se aquelas formas contratuais estão sendo devidamente cumpridas, e a proteção dos direitos de propriedade contra a expropriação por particulares ou o próprio setor público. Finalmente, a correta aplicação do contrato, bem como a cobrança de indenização por prejuízos às partes faltantes ou que não estiverem seguindo corretamente suas obrigações contratuais, e os esforços para recuperar o controle de direitos de propriedade que tenham sido parcial ou totalmente expropriados. (PINHEIRO; SADDI, 2006, p. 62).

Os custos de transação são positivos, haja vista serem os custos necessários para propiciar a atuação do agente econômico em determinado mercado, como, por exemplo, o custo para a obtenção e estruturação do modelo 
jurídico mais adequado a determinado intento. Por isso, a segurança jurídica impacta justamente essa categoria de custos, tendo em vista que mudanças de entendimentos jurisprudencial e/ou a interpretação equivocada de determinado preceito legal aumentará os custos de transação envolvidos para iniciar o negócio jurídico e/ou cobrar o seu adimplemento pela outra parte.

O conceito de custo de transação se encaixa na análise empreendida neste trabalho justamente no que tange à segurança jurídica do mercado de crédito imobiliário envolvendo o procedimento de execução extrajudicial da alienação fiduciária em garantia. É certo que a existência de variados entendimentos jurisprudenciais e/ou a adoção de medidas judiciais de caráter simplesmente assistencial ao mutuário implica no aumento dos custos de transação envolvidos na concessão do financiamento imobiliário.

O custo de transação é, por sua natureza, externo, entretanto, em alguns casos, é possível a sua internalização ocasionando o aumento do preço. Nos casos em que a internalização é inviável e o custo de transação é demasiado elevado, tem-se o abandono pelos agentes de determinada atividade econômica. Pode se dizer, com as devidas adequações, que a crise por qual passou o SFH teve como uma das causas o aumento da insegurança jurídica provocada pela judicialização das relações contratuais e a falta de uniformidade das decisões exaradas.

Ademais, convém explicitar, ainda, os conceitos de seleção adversa e risco moral, bem como os impactos na análise econômica do instituto da alienação fiduciária em garantia de bens imóveis no ordenamento jurídico brasileiro. Ambos os conceitos estão ligados à questão da assimetria das informações detidas pelos agentes econômicos na elaboração e no cumprimento dos contratos.

A "seleção adversa é um problema de assimetria de informações que ocorre antes de efetuada a transação" (NUNES; CALCAVANTE; RIBEIRO, 2008, p. 5) e os agentes que, provavelmente, produzirão resultado indesejado serão selecionados para formação do contrato. No âmbito do mercado de crédito, como é o caso do Sistema Financeiro da Habitação, a seleção adversa é problemática no sentido que os "tomadores de empréstimos que carregam o maior risco" de inadimplência "são mais propensos a tomar empréstimos e a pagar taxa de juros mais altas” (NUNES; CALCAVANTE; RIBEIRO, 2008, p. 6), ocorrendo o aumento da inadimplência os valores cobrados para concessão de empréstimos - juros - tendem a aumentar, em um ciclo. É possível até que os emprestadores decidam diminuir a concessão de novos financiamentos, em 
função da elevada inadimplência ocasionada pela assimetria de informações para identificar o correto risco da operação realizada.

Por outro lado, o risco moral é um problema derivado da assimetria de informações que se dá no "momento pós-contratual da parte que possui uma informação privada e pode dela tirar proveito em prejuízo" da outra parte na transação existente (SZTAJN; ZYLBERSTAJN; AZEVEDO, 2005, p. 123). No que tange aos sistemas financeiros de concessão de crédito, "o risco moral ocorre porque o tomador tem incentivos para alocar os recursos do empréstimo em benefício pessoal ou empreender em projetos sem retorno" (NUNES; CALCAVANTE; RIBEIRO, 2008, não paginado). Nesse contexto, Sztajn, Zylberstajn e Azevedo (2005, p. 124) frisam a relevância do risco moral para o desenho e vinculação dos contratos:

Problemas de risco moral são especialmente relevantes para o desenho de contratos. Para que os deveres acordados no contrato, assim como a transferência dos direitos de propriedade, resultem efetivamente em mudança de comportamento, é necessário que haja informações confiáveis sobre esse comportamento.

Então, há risco moral quando uma parte, detendo informação privilegiada, atua em prejuízo da contraparte por meio de comportamentos que não deveriam ser permitidos e/ou incentivados pela transação existente. Podese citar o caso do Sistema Financeiro da Habitação, no qual muitos mutuários simplesmente deixaram de pagar as parcelas das prestações devidas:

Era comum o abandono puro e simples das moradias ou a suspensão do pagamento das prestações à espera do despejo judicial. Como esses fatos ocorreram em larga escala, muitas famílias chegaram a mora alguns anos "de graça" (...) Essa situação, via de regra, acarretava em uma rápida depreciação das moradias, seja por abandono, ocupação legal ou desleixo do mutuário inadimplente, que passava a não se considerar proprietário do imóvel. (AZEVEDO; ANDRADE, 2011, p. 21).

Percebe-se que os mutuários se valendo das deficiências dos instrumentos 
jurídicos do SFH e da percepção da demora das ações judiciais agiram exatamente da maneira oposta ao previsto no contrato, deixando de efetuar o pagamento das prestações e contribuindo para a deterioração dos bens imóveis dados em garantia, por meio de hipoteca, concretizando-se o risco moral no referido mercado imobiliário.

\section{ANÁLISE ECONÔMICA DA ALIENAÇÃO FIDUCIÁRIA EM GARANTIA DE BENS IMÓVEIS}

A análise econômica do direito é método de análise da legislação tendo em consideração as consequências econômicas advindas do ordenamento. Em suma, a legislação deve ser entendida como um padrão de conduta que incentiva ou não a adoção de determinada conduta. $\mathrm{O}$ desenho institucional deve incentivar condutas economicamente eficientes com o desiderato de diminuir os custos de transação e maximizar a produção e circulação de riquezas (ZYLBERTSZTAJN; SZTAJN, 2005, p. 81).

No contexto do presente trabalho, o próprio instituto jurídico analisado foi criado com o desiderato econômico de promover a segurança na execução da garantia concedida, propiciando, assim, a diminuição da inadimplência e do preço (juros), bem como, por outro lado, incentivando a concessão de novos financiamentos. É importante, então, analisar e verificar se há dados econômicos que corroborem com a eficiência desse instituto jurídico.

Anteriormente a promulgação da Lei Federal de no . 9.514/1997, a garantia imobiliária tradicional firmada para garantir os financiamentos concedidos era a garantia hipotecária que, por diversas razões, não se mostrava eficiente em seu intento de garantir o crédito concedido, "pois apresentavam graves desvantagens pelo custo e morosidade em executá-las" (CHALHUB, apud ABECIP, 1999, p. 45).

Com instituição da alienação fiduciária em garantia, houve a preocupação de tal instituto padecer dos mesmos entraves e questionamentos direcionados às garantias hipotecárias, notadamente no que tange ao procedimento de execução extrajudicial do bem dado em garantia. Luciano Benetti Timm e Tatiana Druck (2007, p. 16) elencam como possíveis bloqueios ao pleno desenvolvimento do referido instituto jurídico a ausência de análise dos impactos econômicos das decisões judiciais e a tendência de politicização do Poder Judiciário.

Em suma, os entraves apontados resumem-se em um só, na insegurança jurídica das decisões judiciais prolatadas, porquanto, segundo os autores, os 
juízes tendem a não considerar que as decisões judiciais têm repercussões econômicas coletivas, notadamente quando se fala de um sistema financeiro que a entrada de novos recursos não pode ser superior a saída, sob pena de se exaurir a possibilidade de novos financiamentos. Além disso, o Poder Judiciário tenderia, como o fez nas garantia hipotecaria, a proteger os mutuários em nome de uma justiça social ou distributiva. Os autores salientam que "enxerga-se, na maioria das vezes, apenas o problema social de acesso à moradia de um lado do processo, e o banco, instituição maximizadora de lucros, de outro" (TIMM; BRUCK, 2007,p. 25), sem que os magistrados percebam que o custo aumentaria em função de tais decisões ditas sociais.

Os autores citam algumas decisões judiciais, envolvendo a alienação fiduciária em garantia, que demonstram a postura paternalista do Poder Judiciário em detrimento das disposições claras e precisas constantes na Lei Federal de $n^{\circ} .9 .514 / 1997$, bem como indo de encontro do objetivo pretendido com a promulgação da referida legislação. Os já citados autores salientam que a alienação fiduciária

[...] daria segurança às operações de financiamento habitacional, dinamizando o mercado desse setor. Contudo, o enfraquecimento do contrato de mútuo causado por precedentes judiciais acaba por enfraquecer a sua garantia, que lhe é acessória. Dificultando o acesso da instituição financeira à recuperação da posse do bem alienado (seja negando liminares de reintegração de posse, seja revisando cláusulas contratuais e garantido o devedor na posse do bem durante a discussão do processo), acaba-se criando um desincentivo para a propagação da alienação fiduciária em garantia no mercado imobiliário. (TIMM; BRUCK, 2007, p. 25).

As preocupações exaradas por Luciano Benetti Tim e Tatiana Bruck, em 2007, são extremamente relevantes, pois demonstrariam que a alienação fiduciária não estaria sendo aplicada eficientemente e, por conta disso, o seu objetivo econômico não teria sido - ou não estaria sendo - atendido. Entrementes, há, atualmente, dados que demonstram que a aplicação da alienação fiduciária em garantia propiciou um aumento da segurança jurídica e, por consequência, uma redução na taxa de inadimplência e o desenvolvimento do mercado (processo social) imobiliário.

O anuário Uqbar de Finanças Estruturadas de 2014, referente às 
operações financeiras estruturadas realizadas em 2013, deixa claro que a alienação fiduciária em garantia causa efeitos positivos para o desenvolvimento do mercado imobiliário, justamente por propiciar uma diminuição na inadimplência e ser uma garantia efetiva:

Vale também destacar outros fatores de relevância que contribuíram para maior oferta de crédito imobiliário em 2013, como o crescimento robusto do saldo consolidado de depósitos na caderneta de poupança -os quais devem ser direcionados para o setor-e a manutenção de baixas taxas de inadimplência dos tomadores de recursos das instituições financeiras. Neste segundo aspecto é importante frisar o efeito positivo paulatino que a alienação fiduciária, como instrumento de garantia efetivo e de uso corrente, vem gerando para o desenvolvimento do mercado de crédito imobiliário. (UQBAR, 2014, p. 63).

A lógica constatada acima é a da eficiência econômica na transmissão da informação adequada aos agentes econômicos, incentivando que esses ajam de maneira eficiente economicamente em sua atuação no processo social denominado mercado. Além disso, a formação do preço, mecanismo que representa as informações do processo produtivo, é influenciada pela eficiência do instituto, porquanto a baixa inadimplência e o desenvolvimento do mercado imobiliário estarão representados no preço do financiamento imobiliário, gerando assim um ciclo de transmissão de informações e preferências no mercado.

Além da constatação da Uqbar, os dados da Associação Brasileira de Crédito Imobiliário demonstram que a taxa de inadimplência dos contratos de financiamento imobiliário está diminuído ao mesmo tempo em que tais financiamentos estão passando a adotar a alienação fiduciária como mecanismo de garantia. Vale, no entanto, frisar que os dados não possibilitam a constatação de uma causa e efeito direta, entretanto não se pode negar a influência dos procedimentos céleres e claros da alienação fiduciária na diminuição da inadimplência. Elaborou-se o gráfico abaixo com relação a diminuição da inadimplência dos contratos de financiamento imobiliário:

Gráfico 1 - Relação da inadimplência dos contratos de financiamento imobiliário 


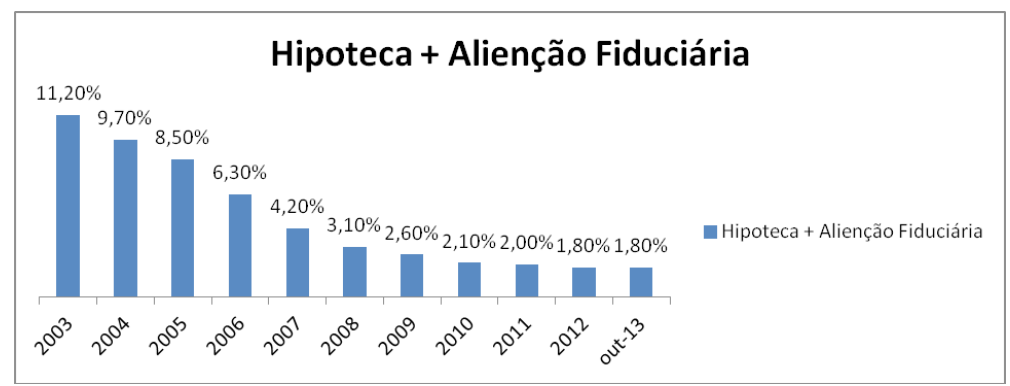

Fonte: ABECIP - Disponível em http://www.abecip.org.br/imagens/apre_octavio_fiabci.pdf

Percebe-se, pelo gráfico acima, que a inadimplência dos contratos de financiamento imobiliário está em ritmo decrescente desde 2003. A questão envolvendo a alienação fiduciária fica mais clara quando se analisa somente a taxa de inadimplência dos contratos garantidos por esse instituto jurídico, conforme gráfico abaixo:

Gráfico 2 - Taxa de inadimplência dos contratos garantidos

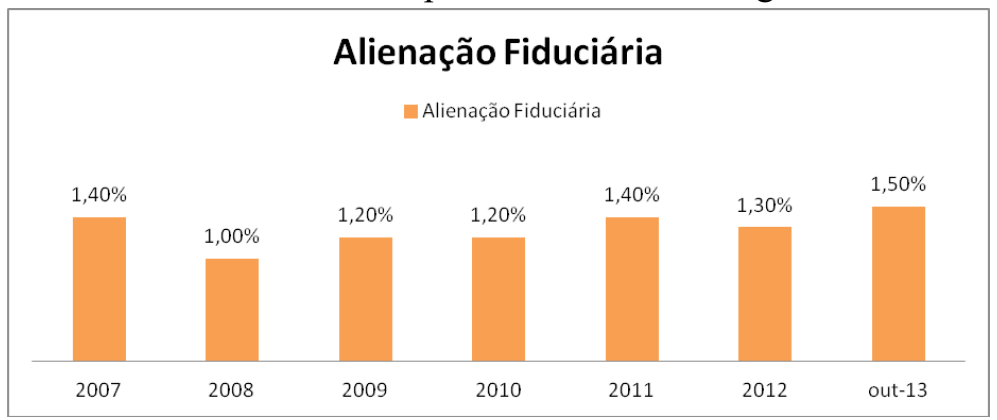

Fonte: ABECIP - Disponível em http://www.abecip.org.br/imagens/apre_octavio_fiabci.pdf

Na comparação entre os dois gráficos tem-se que levar em conta que a maior parte dos contratos de financiamento imobiliários estão atualmente garantidos pelo instituto em análise. Basta rememorar que em 2009 o equivalente a $87 \%$ (oitenta e sete por cento) dos financiamentos imobiliários concedidos 
da Caixa Econômica Federal eram garantidos pela alienação fiduciária em garantia (RESENDE, 2009). Com essa consideração, percebe-se que a taxa de inadimplência dos contratos garantidos pela alienação fiduciária é, proporcionalmente, mais baixa se comparadas com os garantidos por outros meios.

Além da queda na taxa de inadimplência dos contratos de financiamento imobiliário, o próprio mercado imobiliário se desenvolveu nos últimos anos, com o acréscimo de recursos destinados e de imóveis financiados, seja pelo tradicional SFH, com recursos do FGTS e de parcela dos recursos do SBPE, ou pelo SFI, por meio de operações de securitização ou emissão de quotas de Fundos de investimentos. Vale, então, analisar o gráfico abaixo que demonstra a evolução dos financiamentos imobiliários concedidos com recursos do SBPE:

Gráfico 3 - Evolução dos financiamentos imobiliários concedidos pelo SBPE

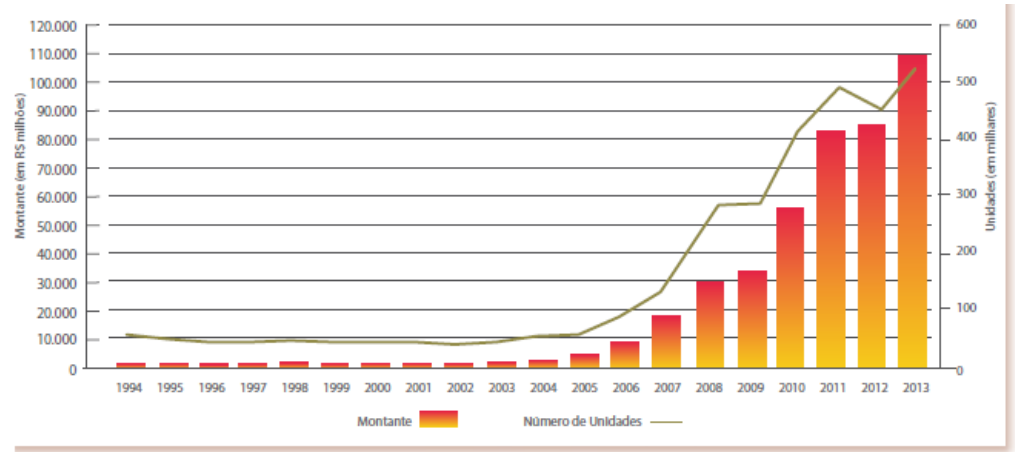

Fonte: Uqbar - Disponível em

http://www.uqbar.com.br/download/UqbarAnuarioImobiliario2014.pdf.

Percebe-se que houve uma evolução na concessão de financiamentos imobiliários tendo por base os recursos captados pelo SBPE, justamente nos anos posteriores a promulgação da Lei Federal de nº 9.514/1997 e sua alteração promovida pela Lei Federal de $n^{\circ}$. 10.931, de 2 de agosto de 2004. Vale frisar, no entanto, que houve diversos outros fatores que ocasionaram o crescimento acima demonstrado, tal como o aumento da captação da caderneta de poupança, a estabilização inflacionária, dentre outros. De igual forma, houve sensível 
aumento dos financiamentos imobiliários concedidos com recursos do FGTS, no âmbito do SFH:

Gráfico 4 - Financiamentos imobiliários concedidos com recursos do FGTS

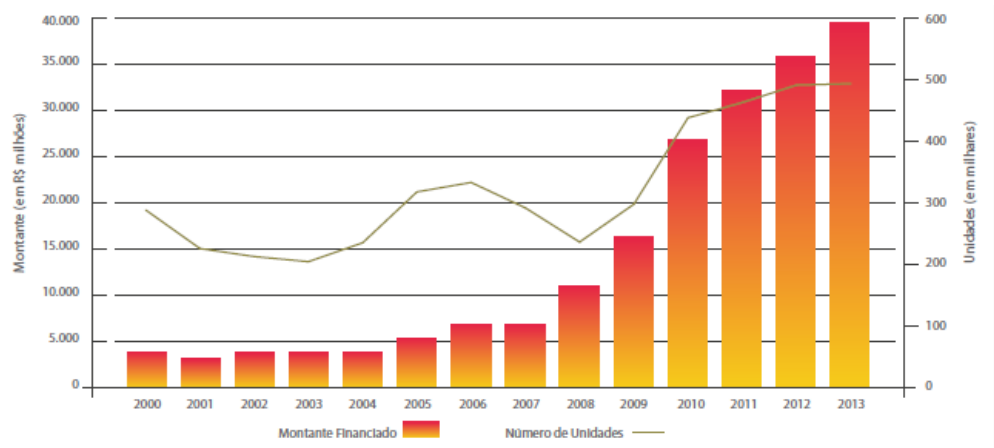

Fonte: Uqbar - Disponível em http://www.uqbar.com.br/download/UqbarAnuarioImobiliario2014. pdf.

Houve um aumento na destinação de recursos e, por consequência, na concessão de financiamentos imobiliários por meio do procedimento tradicional de intermediação financeira, seja por meio de recursos captados junto ao SBPE ou captados junto ao FGTS. Resta evidenciado que houve o desenvolvimento do mercado imobiliário nos últimos anos, até com uma grande quantidade de recursos e financiamentos concedidos no âmbito do SFH.

Por outro lado, uma das intenções da Lei Federal de nº 9.514/1997 era a de propiciar a realização de contratos homogêneos e desenvolver o investimento imobiliário via mercado de capitais. Há, nesse sentido, também dados que demonstram o crescimento do investimento imobiliário via mercado de capitais, por meio de operações de securitização. O gráfico abaixo demonstra a evolução das operações de securitização, especificadamente via emissão de Certificado de Recebível Imobiliário criado no citado diploma legal:

Gráfico 5 - Evolução das operações de securitização 


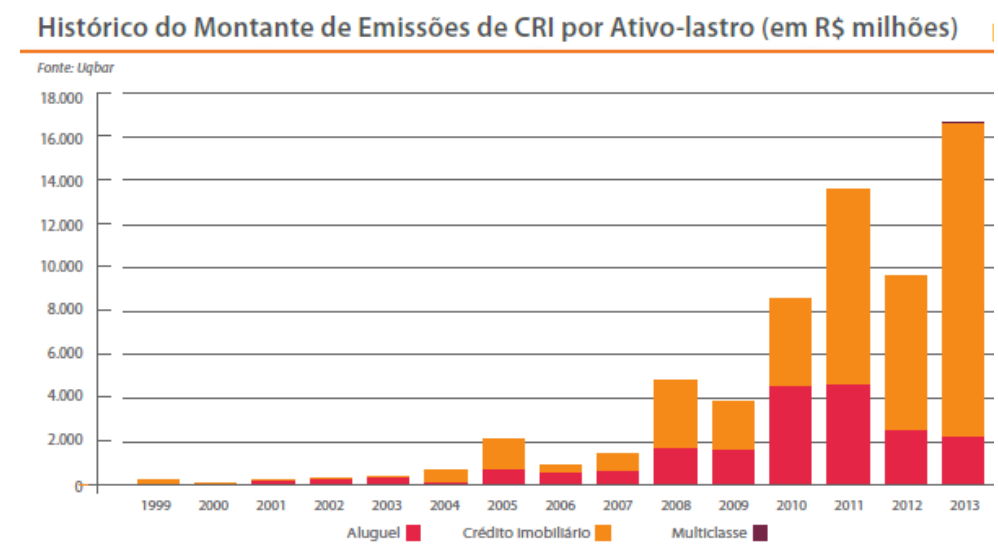

Fonte: Uqbar Disponível em: <http://www.uqbar.com.br/download/UqbarAnuarioFE2014.pdf>

A destinação de recursos via emissão e negociação de Certificados de Recebíveis Imobiliários - CRI's, evoluiu sensivelmente desde a sua criação no ordenamento jurídico pátrio. Vale, nesse ponto, salientar que a maior parte dos cedentes dos créditos imobiliários lastro dos CRI's são provenientes de atividades imobiliárias, presumindo, portanto, que os recursos captados no mercado de capital são direcionados aos empreendedores imobiliários, muito embora o segmento de intermediação financeira seja o segundo no ranking dos cedentes dos certificados emitidos.

Constata-se que houve o crescimento da destinação de recursos via mercado de capitais, contudo será que houve a criação e o fortalecimento de um mercado secundário de negociação dos CRI's emitidos e garantidos pela alienação fiduciária? A resposta é não, praticamente inexistindo negociação realizada após 180 (cento e oitenta) dias a contar da emissão do título (UQBAR, 2014, p. 109).

Os dados econômicos analisados demonstram que a aplicação do instituto jurídico analisado está sendo empreendida de maneira eficiente, porquanto houve a diminuição da taxa de inadimplência e o efetivo aumento dos

\footnotetext{
${ }^{3}$ Art. 53. Nos contratos de compra e venda de móveis ou imóveis mediante pagamento em prestações, bem como nas alienações fiduciárias em garantia, consideram-se nulas de pleno direito as cláusulas que estabeleçam a perda total das prestações pagas em benefício do credor que, em razão do inadimplemento, pleitear a resolução do contrato e a retomada do produto alienado.
} 
recursos liberados para a concessão de financiamentos imobiliários. Além desses dados econômicos, a solução de controvérsia existente quanto à incidência ou não do art. 53 do Código de Defesa do Consumidor ${ }^{3}$, que determina a restituição das parcelas pagas ao devedor, em face das disposições previstas na Lei Federal de $\mathrm{n}^{0}$. 9.514/1997, serviu para garantir a aplicação correta e eficiente do instituto

A discussão doutrinária e jurisprudencial da temática surgiu logo após a promulgação da referida Lei Federal, tendo em vista que a incidência da referida disposição do Código de Defesa do Consumidor iria alterar totalmente o procedimento de execução extrajudicial e de público leilão decorrente da própria lógica da garantia instituída. A solução da questão se deu por meio do julgamento colegiado do Agravo de Instrumento de $\mathrm{n}^{\circ}$. 923.750 - SP, em 2010, no qual restou assentado pelo Superior Tribunal de Justiça o caráter especial e posterior da Lei Federal de nº. 9.514/1997, prevalecendo as suas disposições em face do Código de Defesa do Consumidor. De igual forma, tal situação restou consignada na decisão monocrática proferida pelo Ministro Massami Uyeda, em 2012, nos autos do Recurso Especial de nº 1.160.549 - RS.

Por certo que tais decisões do STJ asseguram a correta aplicação do instituto da alienação fiduciária em garantia de bem imóvel, bem como a diminuição dos custos de transação existentes na concessão de financiamentos imobiliários, e, por isso, permite que tal instituto seja eficiente do ponto de vista econômico, influenciando, com base nos dados elencados, a diminuição da taxa de inadimplência e o desenvolvimento do mercado imobiliário, justamente os seus principais objetivos.

\section{CONCLUSÃO}

A alienação fiduciária em garantia de bens imóveis foi instituída no ordenamento jurídico brasileiro com o desiderato de propiciar segurança aos financiamentos imobiliários concedidos, sendo um direito real sobre imóvel próprio, com a formação de um patrimônio de afetação apto a garantir o pagamento do débito.

Desse objetivo básico, decorre o de possibilitar a redução da taxa de inadimplência dos contratos de financiamentos e o de propiciar o desenvolvimento do mercado imobiliário, com alocação de novos recursos e concessão de novo financiamentos. Esses dois outros intentos são concretizados na medida em que há a correta transmissão de informações no mercado por 
meio da formação adequada do preço. A segurança possibilitada pela alienação fiduciária estará representada no preço do financiamento concedido que, por sua vez, irá informar aos construtores a existência de recursos disponíveis para novas unidades e assim, sucessivamente.

O questionamento inicial do presente trabalho consistia em saber se o instituto jurídico em análise cumpriu - ou está cumprindo - com os objetivos econômicos justificadores de sua instituição, foi respondido de maneira afirmativa, com base nos dados econômicos existentes e nas constatações realizados ao longo do texto. A partir dessa resposta afirmativa pode-se constatar que o referido instituto é eficiente economicamente, pois está induzindo nos agentes envolvidos a realização das condutas pretendidas e benéficas para a sociedade.

Além disso, percebeu-se a alienação fiduciária somente cumpriria com o seu objetivo a partir da correta transmissão de informações no processo social denominado mercado, induzindo, a partir daí, a realização das condutas previstas e eficientes. Diante disso, os dados pesquisados demonstram que, não só existiu a diminuição da taxa de inadimplência, como houve, nos últimos anos, o acréscimo do volume de recursos destinados ao mercado imobiliário, seja via intermediação financeira com recursos do FGTS e do SBPE ou via operações envolvendo o mercado de capitais, como, por exemplo, a emissão de Certificado de Recebíveis Imobiliários. Por último, constatou-se que a superação da discussão envolvendo a aplicação das disposições do art. 53 do Código de Defesa do Consumidor propiciou a elevação da segurança jurídica e, por consequência, a redução dos custos de transação envolvidos na concessão dos financiamentos imobiliários.

\section{REFERÊNCIAS}

ABECIP. Alienação fiduciária e direito do consumidor. São Paulo: ABECIP, 1999.

Paulo: ABECIP, 2013.

\section{. Perspectivas do crédito imobiliário no Brasil. São}

BRASIL. Lei Federal de n⿳0.9.514, de 20 de novembro de 1997. Disponível em: <http://www.planalto.gov.br/ccivil_03/leis/L9514.htm>. Acesso em 2 de 
junho de 2014.

Supremo Tribunal Federal. Agravo de

Instrumento de $\mathbf{n}^{\mathbf{0}}$. 932.750 - SP. Julgado em 25 de maio de 2010. Disponível em: <https://ww2.stj.jus.br/processo/ pesquisa/?tipoPesquisa $=$ tipoPesquisaNumeroRegistro\&termo $=200701799764$ $\&$ totalRegistrosPorPagina $=40$ \&aplicacao $=$ processos $. e a>$. Acesso em 2 de junho de 2014.

. Supremo Tribunal Federal. Recurso Extraordinário de no. 1.160.549 - RS. Julgado em 3 de setembro de 2012. Disponível em: $<$ https://ww2.stj.jus.br/processo/revista/documento/ mediado/?componente $=\mathrm{MON} \&$ sequencial $=21424289 \&$ num registro $=200901915020 \&$ data $=20120903 \&$ tipo $=0 \&$ formato $=P D F>$. Acesso em 2 de junho de 2014.

CHALHUB, Melhim Namem. Negócio fiduciário. 4.ed. rev. e atual. Rio de Janeiro: Renovar, 2006.

COASE, R. H. The nature of the firm. Economica NS, 1937.

. The problem of social cost. Journal of Law and

Economics, v. 3, 1960.

MISES, Ludwig Von. Ação humana. São Paulo: Instituto Ludwig Von Mises Brasil, 2010;

. As seis lições. Tradução de Maria Luiza Borges. 7. ed.

São Paulo: Instituto Ludwig Von Mises Brasil, 2009;

NEGRATO, Gustavo Scudeler. Alienação fiduciária em garantia de bem imóvel: uma análise comparada. Dissertação (Mestrado) - Faculdade de Direito da Pontifícia Universidade Católica, São Paulo, 2010

NUNES, André F. Nunes de; CAVALCANTE, Bruno Maia; RIBEIRO, Bruno Passos Spínola. A crise do subprime sob a ótica da teoria da informação. Disponível em: <http://www.ppge.ufrgs.br/giacomo/arquivos/ 
ecop26/nunes-cavalcante-ribeiro-2008.pdf $>$ acesso em 3 de setembro de 2014.

PINHEIRO, Armando Castelar; SADDI, Jairo. Direito, economia e mercados. Rio de Janeiro: Elsevier, 2005.

RESTIFFE NETO, Paulo; RESTIFFE, Paulo Sérgio. Propriedade fiduciária imóvel. São Paulo: Malheiros Editores, 2009.

REZENDE, Teotônio C. Sustentabilidade do crédito imobiliário: algumas contribuições do Governo Federal e da Caixa. Fortaleza: CEF, 2010. Disponível em: <http://www.bcb.gov.br/pre/evento/ arquivos/2010_3_21/2010_3_17_Painel_III_Teotonio_Rezende.pdf $>$. Acesso em 2 de junho de 2014.

TIMM, Luciano Benetti; DRUCK, Tatiana. A alienação fiduciária imobiliária em garantia em uma perspectiva de direito e economia. California: Berkeley, 2007.

UQBAR. Anuário securitização e financiamento imobiliário 2014, disponível em: <http://www.uqbar.com.br/download/ UqbarAnuarioImobiliario2014.pdf $>$. Acesso em 2 de junho de 2014.

. Anuário finanças estruturadas 2014. Disponível em:

$<$ http://www.uqbar.com.br/download/UqbarAnuarioFE2014.pdf $>$ Acesso em 2 de junho de 2014.

ZYLBERSZTAJN, Decio; SZTAJN, Rachel. Direito e economia. Rio de Janeiro: Elsevier, 2005.

Como citar: COIMBRA, Rodrigo; WITTCKIND, Ellara Valentini. A livre circulação de trabalhadores e a não discriminação ao migrante na União Europeia: digressões acerca da fraternidade e do reconhecimento nas relações de trabalho. Scientia Iuris, Londrina, v. 20, n. 1, p.220- 246 abr. 2016. DOI: 10.5433/2178-8189.2016v20n1p220. ISSN: 2178-8189. 
Submetido em 13/11/2014

Aprovado em 09/03/2016 